\title{
COLLECTION OF OVIDUCT FLUID FROM UNRESTRICTED MONKEYS
}

\author{
K. YOShinaga, W. A. MAHONEY* and the late G. PINGUS
}

Laboratory of Human Reproduction and Reproductive Biology, and

Department of Anatomy, Harvard Medical School, Boston, Mass. 02115, and

The Worcester Foundation for Experimental Biology,

Shrewsbury, Mass. 01545, U.S.A.

(Received 2nd October 1970, revised 19th November 1970)

Hamner \& Fox (1969) have recently reviewed various techniques for the collection of oviduct fluid in the rabbit, sheep, pig and monkey. Continual collection of the oviduct fluid from the rhesus monkey was first achieved by Mastroianni, Shah \& Abdul-Karim (1961). They cannulated the oviducts with silicone rubber tubings which were connected to an external volumetric collection device fixed to the skin. Movements of the animals' upper limbs were restricted with plaster to prevent the animals from reaching the device. Using this technique, daily samples were collected for as long as four complete menstrual cycles.

In view of the possibility that a physical restriction of the monkey might cause a deleterious effect on the normal secretory patterns of the fluid, we developed a device which allows daily collection of the fluid from unrestricted monkeys. The device was installed intra-abdominally and samples were taken for a period of over 3 months, after which, however, the device was subject to rejection by the animal. The technique and preliminary data obtained are described in this report.

Adult female rhesus monkeys, Macaca mulatta, were used. The course of their menstrual cycles was traced by daily vaginal lavage for at least 3 months before the animals were used. The oviduct fluid collection device was installed in four monkeys. Animals were kept in individual cages in a temperature-humidity controlled room and fed with Purina chow, vegetables, fruits, peanuts, dried egg, powdered milk, vitamins and unrestricted water.

During a training period to prepare the monkeys for daily collection of oviduct fluid, each animal was chased out of her cage (the monkey's territory) into an adjacent large enclosure (the man's territory). Here, the handler pursued the animal with a gentle but confident attitude in order eventually to reach and touch the tail and back with bare hands, to accustom her to this procedure and to show that she should not be afraid of being touched. Any charging behaviour was corrected by scolding the animal with a loud voice or, if necessary, by slapping the animal to show the man's superiority in his

* Present address: Biology Department, Imperial Chemical Industries Ltd, Mereside, Alderley Park, Macclesfield SK10 4TG, Cheshire, England. 
territory. Daily training for 1 to 3 weeks was necessary to make the animals stay still while their backs were being touched or rubbed. After training, goodnatured animals even allowed the handler to creep into their cages for the collection of samples.

The collection device was made entirely of silicone rubber (Silastic, Dow Corning, Michigan) and was composed of cannulae, storage block, air vent and aspiration tubing as shown in Plate 1, and Text-fig. 1.

Two cannulae, approximately $4 \mathrm{~cm}$ long ( $1 \mathrm{~mm}$ i.d., $2 \mathrm{~mm}$ o.d.) were glued to the storage block. The free ends of the cannulae were to be inserted into the fimbriated end of the oviducts.

The storage block was made of ten pieces of silicone rubber tubing $(3.2 \mathrm{~mm}$ i.d., $6.4 \mathrm{~mm}$ o.d., $5 \mathrm{~cm}$ long) which were glued together in parallel in two layers. All tubes were connected to form a continuous channel.

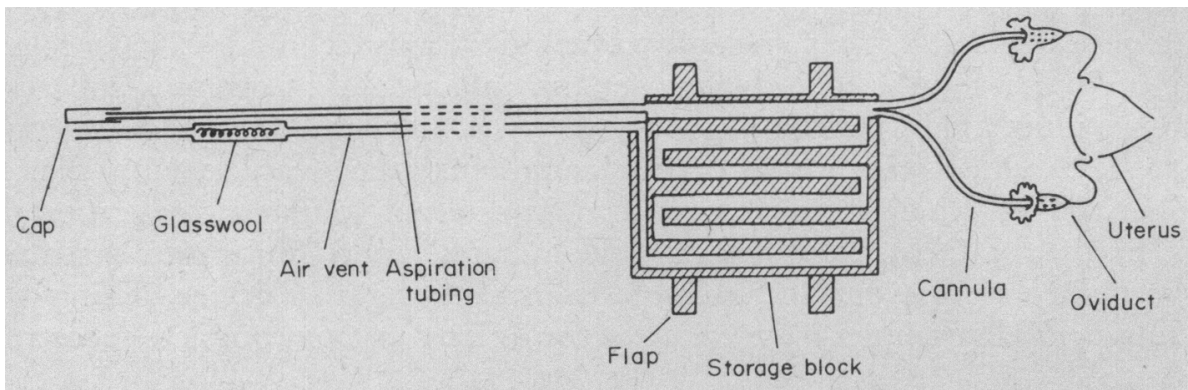

TEXT-FIG. 1. Schematic diagram of the device used for the collection of oviduct fluid in the monkey.

To the storage block, two lengths of tubing $(1 \mathrm{~mm}$ i.d., $2 \mathrm{~mm}$ o.d., $30 \mathrm{~cm}$ long) were inserted and glued. One of these served as air vent and the other for aspirating the fluid. The air vent had a segment $(3 \mathrm{~cm}$ long) in which glass wool was packed lightly to prevent possible contamination. A cap was put over the end of the aspiration tubing. Two strips of silicone rubber sheet reinforced with Dacron mesh were glued on the storage block. They served to anchor the block to the abdominal wall.

The animals were anaesthetized by giving Nembutal intravenously. An abdominal midline incision was made and the oviducts were brought into operating field. The utero-tubal junctions were ligated with 2-0 silk and cannulae of the device were inserted into the fimbriated end of the oviducts and secured by tying the oviduct with the cannula inside. The storage block was fixed inside the abdominal wall by suturing the flaps to the muscle near the midline incision. Air vent and aspiration tubings were brought out through a small incision in the abdominal wall on the right or left flank. The two tubings were then drawn up subcutaneously to a small incision made in the skin between the two scapulae with the aid of a trocar. The length of tubings protruding out of the skin was approximately $5 \mathrm{~cm}$. Oviduct fluid was aspirated daily, starting $24 \mathrm{hr}$ after the operation. A sterile needle with a blunt tip (18G) was connected with a sterile 5-ml syringe, the needle was inserted into the opening of the aspiration 
Pl. $11 \%$ !

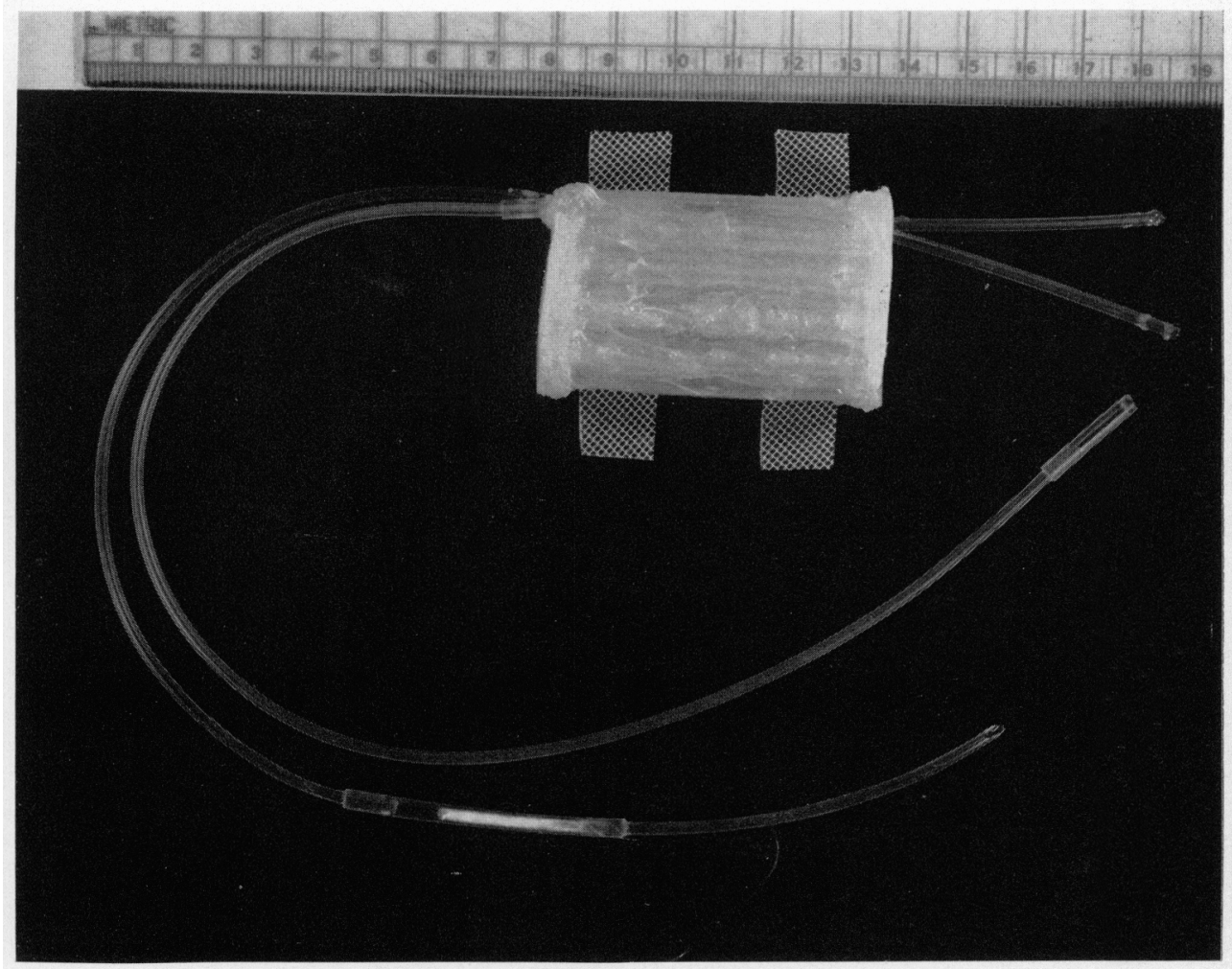

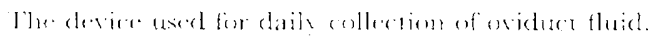


tubing, and fluid was withdrawn. Aspiration was repeated until the whole system was cleared. The volume, colour and nature of the fluid were recorded daily. The secretory pattern of the oviduct fluid during the menstrual cycle is shown in Text-fig. 2. Each circle represents the mean value of six cycles (two cycles which extended between 27 and 33 days in each of three monkeys). The volume of the fluid increased gradually during the follicular phase to reach a peak $(2 \cdot 1 \mathrm{ml}) 15$ days before the next menses. It then diminished to a low level before the menstrual flow. This observation confirms the results obtained by Mastroianni et al. (1961) under different experimental conditions. One of the monkeys, which was excluded from Text-fig. 2, showed a prolonged cycle of 63 days.

During the menses, samples of oviduct fluid containing blood were collected over a period of 1 week. The fluid cleared when its volume increased. Nassberg, McKay \& Hertig (1954) reported that leucostasis, oedema, leucocyte exuda-

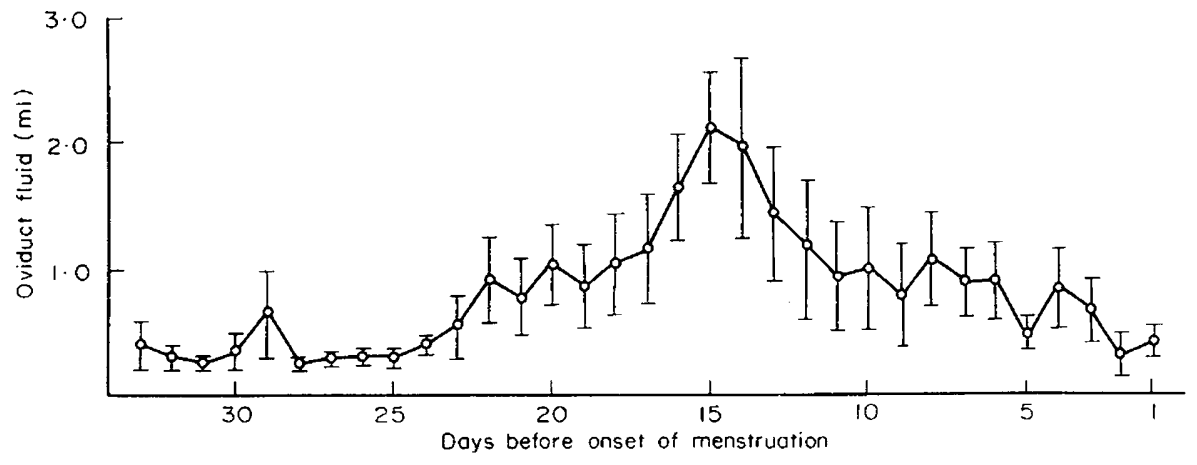

Texr-Fig. 2. Monkey oviduct fluid output during the menstrual cycle. The mean values of six cycles (27 to 33 days) were plotted. Ranges represent standard errors.

tion, red cell débris and a remarkable degree of dilatation of lymphatics occurred in the Fallopian tubes during the period of menstruation in humans. The same phenomenon seems to occur in the monkey.

One of the four monkeys fitted with the device pulled the tubings out 7 days after their installation. The other three monkeys retained the system over 3 months and menstrual cycles of normal length (27 to 33 days) were recorded at least twice for each monkey. However, 66, 83 and 193 days after installation of the device, the volume of daily output dropped to less than $0.2 \mathrm{ml}$ for 66,17 and 6 days, respectively. During these periods, the animals lost their appetites and became inactive. They were, therefore, killed 103, 100 and 199 days after the device had been installed. At autopsy, a massive adhesion was found around the storage block. The adhesion included abdominal wall, omentum and colon. Dissection of the area revealed that the storage block of the device had been taken into the lumen of the colon and was presumably in process of rejection as a foreign body.

This work was supported by a grant from the Population Council, New York. 


\section{REFERENCES}

HAMNER, C. E. \& Fox, S. B. (1969) Biochemistry of oviductal secretions. In: The Mammalian Oviduct, pp. 333-355. Eds. S. E. Hafez and R. J. Blandau. University of Chicago Press.

Mastroianni, L., JR, Shah, U. \& Abdul-Karm, R. (1961) Prolonged volumetric collection of oviduct fluid in the rhesus monkey. Fert. Steril. 12, 417.

Nassberg, S., McKay, D. G. \& Hertig, A. T. (1954) Physiologic salpingitis. Am. F. Obstet. Gynec. 67, 130. 